\title{
Spain in quandary over French synchrotron
}

Xavier Bosch, Barcelona

It has only been in existence for a few weeks, but the Spanish Ministry of Science and Technology is already facing its first major dilemma. The French government has invited Spain to participate in the funding and operation of France's proposed synchrotron, Soleil - but such a move could dash Spanish scientists' long-held hopes for their own machine.

At a meeting two weeks ago in Santander, Spanish and French science officials set up a working group on scientific issues. In particular, the group will address space policy and large scientific equipment, such as the $10-\mathrm{m}$ Gran Telescopio de Canarias (Grantecan) project and the Soleil synchrotron.

Ramón Marimón, state secretary for science and technology policy, says that Spain will take the invitation to participate in Soleil seriously, and is keen to know where the facility would be built. Some observers argue that Spain is more likely to participate in the project if Soleil is built in a southern region of France near to Spain, rather than near Paris.

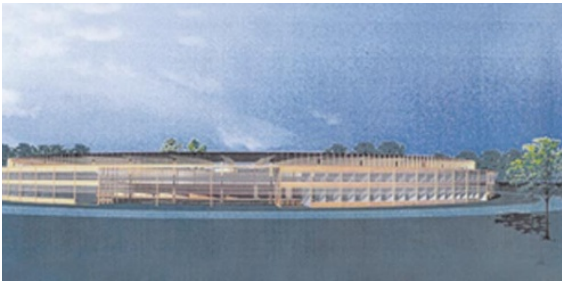

Hot topic: Spain must decide whether to join in with the planned French synchrotron, Soleil.
Marimón says French officials at the Santander meeting were told that the Ptas14 billion (US\$79 million) Grantecan has so far been financed by "national funds only". It is thought that Spain might seek French funding for the telescope - whose foundation stone was laid on 2 June - in return for any contribution to Soleil.

But Marimón says that the Spanish synchrotron, which the government has so far refused to finance, has not been ruled out. In December 1997, a design study was put forward for a $2.5-3 \mathrm{GeV}$ synchrotron light facility called LLS (Laboratori Llum Sincrotro), to be housed at the Autonomous University of Barcelona in Catalonia.

The Catalonian government offered to cover one quarter of the estimated Ptas 13 billion cost, if the national government paid a further quarter, and the European Commission the rest. But the former Office of Science and Technology turned this down in January 1998.

Ten months later, the European Science Foundation (ESF) released a report on the needs for a European synchrotron and related beamlines for biological and biomedical research. Among the medium-term needs, the review panel recommended the construction of new sources, including the LLS.

Enric Banda, ESF general secretary, says the LLS is a "very good project" and adds that, to sort out the north-south imbalance, Europe should have a synchrotron in the south. "If there were to be a facility in southern Europe, Barcelona would be a logical place," he adds.

Andreu Mas-Colell, head of the Catalonian government's Department of Research,

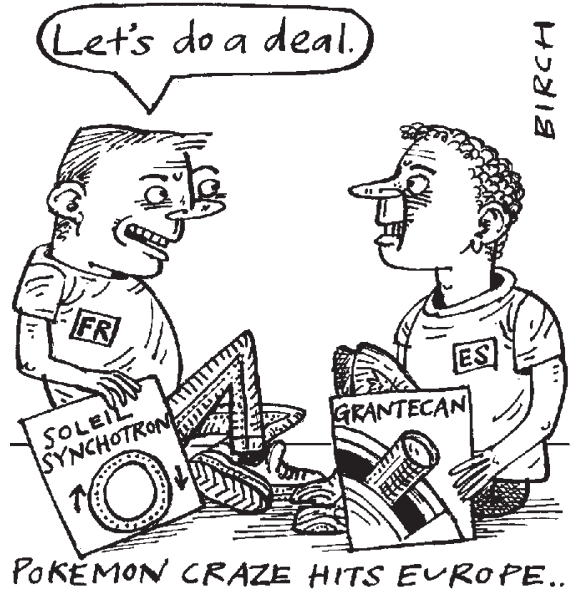

says that although the National Plan on Research, Development and Technological Innovation does not rate a synchrotron as a priority, his department sees a need for a big physics installation. "Hence the LLS is a priority," he says.

Marimón says the Catalonian government's funding formula "seems reasonable". Much like Mas-Colell, LLS director Joan Bordas believes that the traditional scientific rivalry between Madrid and Barcelona may have blocked the project so far. "I don't mind if the facility is built in another Spanish region," he says. "But Spain does need a thirdgeneration synchrotron radiation source."

Grantecan, which the national research plan has prioritized (see Nature 400, 393; 1999), must get 30 per cent of its funding from abroad, but no foreign partner has yet been found.

\section{Immigrants help offset Canada's brain-drain crisis}

\section{David Spurgeon, Montreal}

For years Canada has complained of a 'brain drain' of its best and brightest, lured by higher salaries and better career prospects in the United States. But, according to the country's Liberal government, the latest statistics indicate that it might be experiencing more 'gain' than 'drain'.

An article in the May issue of Education Quarterly Review, a publication of the Canadian federal body Statistics Canada, says the country gained four university graduates from abroad for every one it lost to the United States. Furthermore, Canada received as many immigrants with a master's degree or doctorate as it lost university graduates at all levels to the United States.

The analysis confirms the widely held perception that the loss of highly skilled workers to the United States accelerated during the 1990s. But so too did the influx of such individuals from abroad: about onethird of the increase in employment among computer engineers, programmers and systems analysts during the decade consisted of immigrants, many coming from developing countries.

During the 1990s, between 22,000 and 35,000 people a year are estimated to have emigrated from Canada to the United States, either temporarily or permanently. They were more likely to be graduates and have higher incomes than the Canadian population as a whole. Analysis of income tax data showed that individuals earning more than Can\$150,000 (US\$100,000) a year were seven times as likely to leave as the average taxpayer.

Most of those who left were in the 23-44 age group. Many worked in hospitals, education and high-technology industries

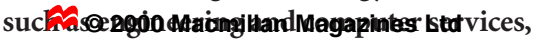
precisely the 'knowledge-intensive' sectors that the federal government has emphasized as important to the Canadian economy.

But from the mid-1980s to 1997, the most recent year for which statistics are available, permanent immigration to Canada increased 15-fold among computer scientists, 10-fold among engineers, eightfold among natural scientists and fourfold among managerial workers. In 1997, more than 20,000 immigrants intended to work as computer scientists, engineers and natural scientists.

Canadian business leaders have often complained about the lack of recruits for the country's hi-tech industries. Thomas d'Aquino, chief executive officer of the Business Council on National Issues, says the study does not show that Canada has no problem. "If we didn't have a brain gain from immigration, we'd be in really serious trouble," he says. 